\title{
Desorption of polycyclic aromatic hydrocarbons from field- contaminated soil to a two-dimensional hydrophobic surface before and after bioremediation
}

\author{
Jing Hu and Michael D. Aitken * \\ Department of Environmental Sciences and Engineering Gillings School of Global Public Health \\ University of North Carolina Chapel Hill, NC 27599-7431, U.S.A.
}

\section{Abstract}

Dermal exposure can represent a significant health risk in settings involving potential contact with soil contaminated with polycyclic aromatic hydrocarbons (PAHs). However, there is limited work on the ability of PAHs in contaminated soil to reach the skin surface via desorption from the soil. We evaluated PAH desorption from a field-contaminated soil to a two-dimensional hydrophobic surface (C18 extraction disk) as a measure of potential dermal exposure as a function of soil loading (5 to $100 \mathrm{mg}$ dry soil $\left./ \mathrm{cm}^{2}\right)$, temperature $\left(20^{\circ} \mathrm{C}\right.$ to $40{ }^{\circ} \mathrm{C}$ ), and soil moisture content $(2 \%$ to $40 \%$ ) over periods up to $16 \mathrm{~d}$. The efficacy of bioremediation in removing the most readily desorbable PAH fractions was also evaluated. Desorption kinetics were described well by an empirical two-compartment kinetic model. $\mathrm{PAH}$ mass desorbed to the $\mathrm{C} 18$ disk kept increasing at soil loadings well above the estimated monolayer coverage, suggesting mechanisms for $\mathrm{PAH}$ transport to the surface other than by direct contact. Such mechanisms were reinforced by observations that desorption occurred even with dry or moist glass microfiber filters placed between the C18 disk and the soil. Desorption of all PAHs was substantially reduced at a soil moisture content corresponding to field capacity, suggesting that transport through pore air contributed to PAH transport to the $\mathrm{C} 18$ disk. The lower molecular weight PAHs had greater potential to desorb from soil than higher molecular weight PAHs. Biological treatment of the soil in a slurry-phase bioreactor completely eliminated PAH desorption to the $\mathrm{C} 18$ disks.

\section{Keywords}

PAHs; desorption; soil; dermal exposure; bioremediation

\section{Introduction}

Polycyclic aromatic hydrocarbons (PAHs) are of great concern because of their known or suspected genotoxicity, mutagenicity and carcinogenicity (Santodonato, 1997; Bostrom et al., 2002). Dermal exposure can represent a significant health risk in settings involving potential contact with complex materials containing PAHs, including PAH-contaminated

\footnotetext{
(C) 2012 Elsevier Ltd. All rights reserved.

*Corresponding author. Tel.: +1 919966 1024; fax: +1 9199667911 mike_aitken@unc.edu.

Appendix A. Supplementary material

jinghu@live.unc.edu(J. Hu); mike_aitken@unc.edu (M. D. Aitken)

Publisher's Disclaimer: This is a PDF file of an unedited manuscript that has been accepted for publication. As a service to our customers we are providing this early version of the manuscript. The manuscript will undergo copyediting, typesetting, and review of the resulting proof before it is published in its final citable form. Please note that during the production process errors may be discovered which could affect the content, and all legal disclaimers that apply to the journal pertain.
} 
soil or sediment (Boffetta et al., 1997; Sobus et al., 2009). Most previous work has been concerned with integrated uptake of chemicals through the skin and not with how a contaminant reaches the skin surface in the first place. However, only a contaminant that reaches the skin surface is available for dermal absorption (Roy et al., 1998; Shatkin et al., 2002). Desorption properties, such as dynamic conditions by which soil contacts the skin, interactions of the soil with the skin surface and chemical interaction with the soil, have been identified to influence dermal uptake of chemicals (McKone and Howd, 1992; Spalt et al., 2009). Therefore, it is important to understand desorption of PAHs from contaminated soil or sediment to the skin surface.

To account for the association of hydrophobic contaminants such as PAHs with compartments of varying sorptive strength in soil (Alexander, 1995; Xing and Pignatello, 1997; Cornelissen et al., 2005), a so-called two-compartment desorption model assumes a simplified situation in which a fraction of the contaminant is released relatively rapidly and the remainder is released relatively slowly (Cornelissen et al., 1998; Hawthorne et al., 2001; Zhu et al., 2008). By incorporating two-compartment desorption kinetics into a fugacity model, Shatkin et al. (2002) illustrated that a greater rapid-desorbing fraction of a chemical would result in greater dermal uptake. In most previous experimental work on dermal uptake of contaminants from soil, an individual contaminant was introduced into the soil through a solvent that subsequently evaporated (Spalt et al., 2009). However, exposure to a spiked chemical does not account for the effect of contaminant aging that would have occurred in field-contaminated soil (Roy et al., 1998; Stroo et al., 2000; Spalt et al., 2009), which is well known to decrease its bioavailability (Alexander, 2000).

The objective of this study was to evaluate desorption of PAHs from field-contaminated soil from a former MGP site to a two-dimensional hydrophobic surface (Empore ${ }^{\mathrm{TM}} \mathrm{C} 18$ extraction disk) as a measure of potential dermal exposure. Various factors affecting desorption were investigated, including soil loading, temperature, soil moisture content (SMC), and exposure time. We also compared desorption to the C18 disk to a conventional method of evaluating potential contaminant bioavailability in soil, desorption to Tenax ${ }^{\circledR}$ beads in a well-mixed aqueous slurry (Loehr et al., 2003). The efficacy of bioremediation (in a slurry-phase bioreactor) in removing the most readily desorbable PAH fractions was evaluated with both methods.

\section{Materials and methods}

\subsection{Materials}

Source soil used in this study was collected from a former MGP site in Salisbury, North Carolina, USA. Samples were air-dried, sieved $\left(250 \mu \mathrm{m}\right.$ mesh) and maintained at $4{ }^{\circ} \mathrm{C}$ prior to use. The total organic matter fraction $\left(f_{o c}\right)$ was 0.16 (dry mass basis, wt $/ \mathrm{wt}$ ), SMC was $2.0 \%\left(\mathrm{wt} / \mathrm{wt}\right.$ ), field capacity was $40 \%$ (wt/wt), and soil particle density was $2.57 \mathrm{~g} / \mathrm{cm}^{3}$ (methods are identified in Table S1, Supplementary Material). The total concentration of 14 target PAHs (the 16 priority PAHs, excluding acenaphthylene and indeno[1,2,3-cd]pyrene) was $780 \pm 10 \mathrm{mg} / \mathrm{kg}$ (dry mass basis, wt/wt; individual PAH concentrations are shown in Table S2); the most abundant PAHs were phenanthrene (PHE, $322 \pm 5.1 \mathrm{mg} / \mathrm{kg}$ ) and pyrene (PYR, $121 \pm 0.05 \mathrm{mg} / \mathrm{kg}$ ). Soil samples were mixed with de-ionized water to reach desired SMC levels prior to desorption experiments. Treated soil was the slurry from a continuously stirred, semi-continuous (draw and fill), laboratory-scale aerobic bioreactor (Zhu et al., 2008) treating the source soil. The treated soil had a total PAH concentration of $121 \pm 8 \mathrm{mg} /$ $\mathrm{kg}$ (individual PAH concentrations are shown in Table S2).

Empore ${ }^{\mathrm{TM}} \mathrm{C} 18$ extraction disks ( $25 \mathrm{~mm}$ diameter, $0.5 \mathrm{~mm}$ thickness) were obtained from $3 \mathrm{M}$ (St. Paul, MN, USA) and cleaned by acetone extraction overnight and air-dried before 
use. Tenax ${ }^{\circledR}$ TA beads (60/80 mesh) were purchased from Alltech (Deerfield, IL, USA) and cleaned by Soxhlet extraction in acetone: hexane (50:50, v/v) mixture overnight and airdried before use. PAH standards (EPA 610 PAHs Mixture) were obtained from SigmaAldrich (St. Louis, MO, USA). Anthracene-D10 was obtained from Cambridge Isotope Laboratories (Andover, MA, USA). Solvents were high-pressure liquid chromatography (HPLC) grade and were obtained from Fisher Scientific (Pittsburgh, PA, USA).

The $\mathrm{C} 18$ extraction disks were used to evaluate variables that might influence the transfer of PAHs from soil to a static hydrophobic interface. This method is analogous to the Tenax beads method for evaluating PAH desorption kinetics in slurry systems (Loehr et al., 2003), in that both $\mathrm{C} 18$ extraction disks and Tenax beads serve as an infinite sink; however, we believe that the $\mathrm{C} 18$ disk is more relevant to the application of soil to skin in a dermal exposure scenario.

\subsection{Desorption experiments}

Desorption of PAHs from soil samples to $\mathrm{C} 18$ disks was determined at three different temperatures $\left(20^{\circ} \mathrm{C}, 30^{\circ} \mathrm{C}\right.$ and $\left.40{ }^{\circ} \mathrm{C}\right)$, four SMC levels $(2 \%, 8 \%, 20 \%$ and $40 \%)$ and seven soil loadings ( 5 to $100 \mathrm{mg}$ dry soil $/ \mathrm{cm}^{2}$ ) over periods of $6 \mathrm{~d}$, when total PAHs desorbed from soil to a C18 disk reached an apparent equilibrium (Fig. S1). Kinetics for desorption of PAHs from soil to $\mathrm{C} 18$ disks were investigated over periods of $16 \mathrm{~d}$. The sorption capacity of C18 disks was evaluated by repeated soil loading of the same disk; results indicated that the sorption capacity greatly exceeded the amount of PAHs desorbed in any given experiment (Table S3). Soil with a specified SMC level was spread as evenly as possible (under microscopic observation) onto the $\mathrm{C} 18$ disk, which was then transferred with an aluminum spatula onto an aluminum weighing dish. Soil weight was determined by weight difference of the $\mathrm{C} 18$ disk before and after soil loading. The aluminum weighing dish was then transferred into a sealed container and kept in the dark in a constant-temperature room set to the desired temperature. After each desired time interval, disks were removed and rinsed with de-ionized water three times for subsequent PAH extraction. To investigate possible mechanisms of PAH transport from soil to the hydrophobic surface, dry or moist Whatman glass microfiber filters (pore size $0.7 \mu \mathrm{m}$, pre-baked at $400^{\circ} \mathrm{C}$ for $4 \mathrm{~h}$ ) (Fisher Scientific, Pittsburgh, PA, USA) were placed between the C18 disk and the soil. Triplicates of procedure blanks (no soil) were included. Total PAH recovery over all experiments was $94 \pm 6 \%$ (individual PAH recoveries are shown in Table S4), calculated by comparing the initial PAH mass in the soil with the PAH mass desorbed to the C18 disk and the PAH mass remaining in the soil after desorption.

Desorption of PAHs from soil to Tenax beads was carried out at $20{ }^{\circ} \mathrm{C}$. Approximately $3 \mathrm{~g}$ of soil (dry wt.) and $0.2 \mathrm{~g}$ Tenax beads were suspended in $20 \mathrm{~mL}$ phosphate buffer ( $\mathrm{pH} 7.5)$ amended with $4.15 \mathrm{~g} / \mathrm{L} \mathrm{NaN}_{3}$ in a $30-\mathrm{mL}$ glass serum vial with a PTFE-lined septum and screw cap. The vials were placed on a wrist-action shaker at $240 \mathrm{rpm}$ in the dark. After 1,2, 4, 8 and 16d, the vials were centrifuged at $3500 \mathrm{rpm}$ for $15 \mathrm{~min}$, Tenax beads were removed from the vials for subsequent extraction as described by Zhu et al. (2008), and the supernatant was discarded. For all but the 16-d time point, $20 \mathrm{~mL}$ fresh medium was added along with $0.2 \mathrm{~g}$ fresh Tenax beads into the vials. The mass recovery of Tenax beads over all time points was $97 \pm 2 \%$. Total PAH recovery was $92 \pm 10 \%$ for combined experiments with source soil and treated soil (individual PAH recoveries are in Table S4).

\subsection{PAH extraction and analysis}

C18 disks and Tenax beads were extracted with $10 \mathrm{~mL}$ acetone and $10 \mathrm{~mL}$ methanol, respectively, in a 20-mL test tube with a PTFE-lined septum and screw cap; each tube was amended with $20 \mu \mathrm{L}$ anthracene-D10 $(100 \mu \mathrm{g} / \mathrm{L})$ as recovery surrogate. The tubes were 
placed on a wrist-action shaker at $240 \mathrm{rpm}$ in the dark for $24 \mathrm{~h}$. A 1-mL aliquot of extract from the $\mathrm{C} 18$ disk was then removed for HPLC analysis. The extract from Tenax beads was filtered through a Millipore (Billerica, MA, USA) nylon membrane (pore size $0.20 \mu \mathrm{m}$ ) to remove the beads and subsequently analyzed by HPLC. Soil samples were extracted overnight twice each with a mixture of $10 \mathrm{~mL}$ acetone and $10 \mathrm{~mL}$ dichloromethane as described elsewhere (Zhu et al., 2008). All extracts were analyzed by HPLC (Zhu et al., 2008).

\subsection{Data analysis}

SPSS ${ }^{\circ}$ (v16.0, SPSS Inc.) was applied for data analysis. One-way ANOVA followed by Tukey's test was employed to test for differences among multiple groups. The maximum soil loading required to provide monolayer coverage was estimated according to Eq. 1 (Duff and Kissel, 1996) assuming solid spherical soil particles and face-centered packing:

$$
S L_{\text {monolayer }}=\frac{\rho_{\text {particle }}\left(\pi d^{3} / 6\right)}{d^{2}}=\rho_{\text {particle }}(\pi d / 6)
$$

where $S L_{\text {monolayer }}$ is the soil loading representing a monolayer $\left(\mathrm{mg} / \mathrm{cm}^{2}\right) ; \rho_{\text {particle }}$ is the soil particle density $\left(\mathrm{g} / \mathrm{cm}^{3}\right) ; d$ is the soil particle diameter $(\mu \mathrm{m})$. Desorption kinetics data were evaluated with the commonly used two-compartment kinetic model, Eq. 2 (Cornelissen et al., 1998; Hawthorne et al., 2001; Zhu et al., 2008):

$$
\frac{S_{0}-S_{t}}{S_{0}}=1-f_{r} e^{-k_{r} t}-f_{s} e^{-k_{s} t}
$$

where $S_{0}$ is the initial soil concentration of a given PAH $(\mu \mathrm{g} / \mathrm{g}) ; S_{t}$ is the soil concentration at time $t(\mu \mathrm{g} / \mathrm{g}) ; f_{r}$ and $f_{S}$ are the fractions of the PAH that desorb rapidly and slowly, respectively; $k_{r}$ and $k_{S}$ are the rate constants for rapid and slow desorption, respectively $\left(d^{-1}\right)$; and $t$ is the desorption time $(d)$. All model parameters with their standard errors and coefficients of determination were determined using nonlinear regression.

\section{Results}

\subsection{Effects of soil loading, temperature and SMC on desorption to C18 disks}

The mass of PAHs desorbed from soil to a $\mathrm{C} 18$ disk increased with increasing soil loading, although the percentage desorbed decreased as loading increased (Fig. 1). According to Eq. 1 , the maximum soil loading required to provide monolayer coverage was estimated as no more than $34 \mathrm{mg} / \mathrm{cm}^{2}$ with soil particle density of $2.57 \mathrm{~g} / \mathrm{cm}^{3}$ and soil particle diameter less than $250 \mu \mathrm{m}$ (soil was sieved through $250 \mu \mathrm{m}$ mesh). It is obvious from Fig. 1 that the total PAH mass desorbed to the $\mathrm{C} 18$ disk kept increasing at soil loadings well above the estimated monolayer coverage.

Soil loading effects on PAH desorption to C18 disks was influenced by temperature, but the influences depended on the specific PAH (Fig. S2). For naphthalene (NAP), the mass desorbed was constant for all soil loadings at each of the three temperatures evaluated (20, 30 and $40{ }^{\circ} \mathrm{C}$ ). For acenaphthene (ACE) and fluorene (FLU), the mass desorbed was proportional to soil loading at each temperature. For phenanthrene (PHN), anthracene (ANT), fluoranthene (FLA) and pyrene (PYR), the mass desorbed asymptotically approached a maximum that appeared to have been reached for each compound at $20{ }^{\circ} \mathrm{C}$ and $30{ }^{\circ} \mathrm{C}$ over soil loadings up to $100 \mathrm{mg} / \mathrm{cm}^{2}$. The asymptote generally tended to be approached at higher soil loadings as temperature increased. In separate experiments, we 
verified that the apparent maximum mass of PAH desorbed did not approach the sorption capacity of the C18 disk (Table S3).

Increased desorption of PAHs to the $\mathrm{C} 18$ disk at soil loadings well above monolayer coverage suggested that PAHs were transferred to the disk by mechanisms other than direct soil contact. Accordingly, with a fixed soil loading above monolayer coverage $\left(40 \mathrm{mg} / \mathrm{cm}^{2}\right)$, we evaluated the extent to which placing a barrier to direct contact between the soil and the disk would affect desorption. The desorption of PAHs from soil to the C18 disk still occurred even with a dry or moist glass microfiber filter placed between the hydrophobic surface and the soil (Fig. 2). For NAP, ACE and FLU, there were no significant differences between desorption with a dry or a moist filter and that without a filter. However, for PHN, ANT, FLA and PYR, desorption from the soil to the C18 disk was significantly lower with a dry or a moist filter than without a filter; in addition, desorption was significantly lower in the presence of a moist filter than in the presence of a dry filter. Desorption in the presence of two dry or two moist filters was only slightly less than in the presence of only one dry or one moist filter for all PAHs (data not shown). No PAH was detected in the dry or moist filter that was not in direct contact with the soil, suggesting that PAHs were not sorbed by the filters.

The desorption of all PAHs to the C18 disk with a fixed soil loading well above monolayer coverage $\left(50 \mathrm{mg} / \mathrm{cm}^{2}\right)$ was substantially reduced at an SMC of $40 \%$, which corresponded to approximate field capacity of the soil (Fig. 3). Desorption of total PAHs from soil at an SMC of $40 \%$ was only one-third of that at an SMC of 2\%. For NAP, ACE, FLU and PHN, there were no significant differences between desorption from soil at SMC from $2 \%$ to $20 \%$. For ANT, FLA and PYR, there was no significant difference between desorption from soil at SMC of $2 \%$ and $8 \%$; at an SMC of $20 \%$ there was a statistically significant, but modest, decrease in desorption.

\subsection{Effects of bioremediation on desorption to $\mathrm{C} 18$ disks and to Tenax beads}

Desorption of PAHs to C18 disks from both the source soil and the biologically treated soil was compared to desorption to Tenax beads in a vigorously mixed aqueous slurry (Fig. 4). For the source soil, only $62 \%$ of the total PAHs desorbed to Tenax beads was desorbed to C18 disks. Lower molecular weight PAHs had greater potential to desorb from soil than higher molecular weight PAHs; the percentage desorption both to Tenax beads and to C18 disks decreased as PAH molecular weight increased. For the biologically treated soil, desorption to $\mathrm{C} 18$ disks was not observed for any PAH (data not shown), suggesting that biological treatment of the soil in an aerobic, slurry-phase bioreactor removed the fraction of each PAH that was capable of desorbing to the $\mathrm{C} 18$ disk. The percentage desorption of all PAHs from biologically treated soil to Tenax beads was much lower than that from the source soil, reinforcing that the most bioavailable fractions of the PAHs had been removed by biological treatment.

Desorption kinetics of each individual PAH from source soil to both $\mathrm{C} 18$ disks and Tenax beads were described well by the commonly used two-compartment kinetic model (Eq. 2), as illustrated in Fig. S3. Fitted parameter values are summarized in Table S5. The rapidly desorbing fraction $\left(f_{r}\right)$ for desorption from the source soil to Tenax beads was higher than that for desorption to the $\mathrm{C} 18$ disk. For desorption of PAHs from the biologically treated soil to Tenax beads, $f_{r}$ was not significantly different from 0 for any PAH. The rate constant for the slowly desorbing fraction $\left(k_{S}\right)$ for biologically treated soil was lower than that for source soil in the Tenax-bead system. 


\section{Discussion}

Current guidance from the US Environmental Protection Agency (USEPA) for assessment of dermal exposure to contaminants in soil (USEPA, 2004) stipulates a fixed percentage absorption (13\%) for dermal uptake of benzo[a]pyrene and other PAHs based on measurements from a single study (Wester et al., 1990). Although this single value simplifies human health risk calculation, it doesn't account for the effects of soil loading configuration on dermal absorption. Bunge and Parks (1998) proposed two distinct situations based on a mathematical model describing dermal absorption of organic chemicals from contaminated soils for a given exposure time. When soil loading is less than monolayer coverage, the percentage absorption remains constant as soil loading increases while the mass absorbed per unit skin area dramatically increases; when soil loading exceeds monolayer coverage, the percentage absorption decreases significantly as soil loading increases while the mass absorbed per unit skin area remains constant. Several investigators have confirmed these results experimentally (Duff and Kissel, 1996; Roy and Singh, 2001; Touraille et al., 2005). However, such predictions are based on the assumption that the contaminant concentration in the soil remains constant (i.e., percentage absorption less than $10 \%$ of applied dose) during dermal absorption (Bunge and Parks, 1998). When the contaminant is depleted from the soil, the percentage absorption would decrease with increasing soil loading above monolayer coverage while the mass absorbed would increase disproportionately (Bunge and Parks, 1998). This prediction is consistent with our observation that the mass of PAHs desorbed from soil to the hydrophobic surface disproportionately increased with increasing soil loading well above monolayer coverage while the percentage desorption was more than $10 \%$ of the applied dose (Fig. 1). Touraille et al. (2005) also observed the phenomenon that the mass of 4-cyanophenol (CP) absorbed increased with increasing soil loading above monolayer coverage for an exposure time of 24 h.

The increasing mass of PAH desorbed at soil loadings beyond monolayer coverage demonstrated that not only the contaminants in a monolayer of soil particles in direct contact with the hydrophobic surface were desorbed. One explanation for this result is the depletion of PAHs in the soil, thus establishing concentration gradients away from the surface (Bunge and Parks, 1998). Since the soil was unstirred, the concentration of a desorbable chemical in the soil will depend on the distance from the hydrophobic surface. As chemicals in soil layers closer to the hydrophobic surface become depleted, the concentration gradient provides a larger driving force for chemicals in upper soil layers to diffuse toward the hydrophobic surface. However, it is difficult to experimentally confirm concentration gradients through the soil depth.

We propose that contaminants can move from the soil to the hydrophobic surface through a combination of three processes: direct contact transfer from soil solids, diffusion through soil pore air, and diffusion through soil pore water. The pore air and pore water transport pathways would be most important at soil loadings beyond monolayer coverage of the hydrophobic surface. Transport through pore air is likely to be more significant because diffusivity in air is far greater than that in water (Schwarzenbach et al., 2003), and air would be the predominant fluid phase in pores for soil moisture contents below field capacity. Also, soil-to-air diffusion of PAHs and other volatile and semi-volatile organic pollutants is well-documented (Meijer et al., 2003; Ribes et al., 2003; Yang and Holmen, 2008). This hypothesis is supported by our finding that the mass of PAHs desorbed from the soil to the hydrophobic surface was considerable even when dry or moist glass microfiber filters were placed between the hydrophobic surface and the soil (Fig. 2). These filters prohibited transfer of PAHs from soil solids to the hydrophobic surface by direct contact. Transport by mechanisms other than direct contact was most significant for the lower-molecular weight 
PAHs (NAP, ACE, and FLU; Fig. 2) that also have the highest vapor pressures (summarized in Table S6). Although soil moisture contents below field capacity had a limited effect on PAH desorption from the soil, the significant reduction of PAH desorption to the C18 disk at SMC corresponding to field capacity (Fig. 3) also suggests that PAH diffusion in pore air was a predominant mechanism of transport to the $\mathrm{C} 18$ disk.

Besides soil loading configuration, other site-specific properties may also influence desorption of PAHs from soil to a two-dimensional hydrophobic surface. Temperature is one of these factors, as diffusion coefficients are positively correlated with temperature (Schwarzenbach et al., 2003). We observed inconsistent effects of temperature on desorption to the $\mathrm{C} 18$ disks. For several compounds (ACE, FLU, and ANT), the effect of temperature was limited (Fig. S2). For the remaining compounds (NAP, PHN, FLA, and PYR), the effect of temperature on desorption was substantial (Fig. S2). Several other investigators have also observed a positive relation between temperatures and desorption of semi-volatile compounds from soil to air (Hippelein and McLachlan, 2000; He et al., 2009). Overall, the effect of temperature in our work would not be easy to predict, as temperature affects not only the soil-air partitioning equilibrium and PAH diffusivity, but the PAH-C18 sorption equilibrium as well; these effects of temperature could be counter-acting for a given PAH.

Bioremediation can be an attractive remediation approach for PAH-contaminated systems (Aitken and Long, 2004). In this study, treatment of the source soil in an aerobic bioreactor reduced total PAH concentration by approximately $80 \%$ (Table S2) and seemed to eliminate the most readily desorbable fraction of all PAHs (Fig. 4). Similar decreases in the rapidly desorbed fractions of PAHs after bioremediation have also been observed in previous research (Cornelissen et al., 1998; Hawthorne et al., 2001; Richardson and Aitken, 2011). For the treated soil, no PAH desorption to $\mathrm{C} 18$ disks was observed, and there was no rapidly desorbing fraction in the slurry-based Tenax bead desorption system. It therefore appeared that biological treatment eliminated the PAHs that could desorb to a two-dimensional surface, and thus might substantially decrease the dermal bioavailability of PAHs in contaminated soil.

The default assumption for exposure time in dermal exposure assessments for contaminated soil is $24 \mathrm{~h}$ (USEPA, 2004). Although we carried out most of our experiments over a six-day period, the majority of the desorbed PAH mass desorbed within $24 \mathrm{~h}$ (Fig. S1). The experiments we performed are easily modified to 24-h duration if desired for an actual exposure analysis. We also recognize that skin is a complex matrix containing both hydrophobic and hydrophilic compartments as well as metabolic enzymes. A uniformly hydrophobic surface might overestimate the flux of PAHs from soil to the skin surface and/ or neglect the metabolism of PAH by skin. The more important point is that dermal exposure assessment from soil should consider site-specific conditions that influence the bioavailability of hydrophobic contaminants to skin. The effects of remediation on potential dermal exposure should consider not only the reduction in contaminant concentration but also the reduction in contaminant bioavailability.

\section{Supplementary Material}

Refer to Web version on PubMed Central for supplementary material.

\section{Acknowledgments}

This work was supported by the National Institute of Environmental Health Sciences Superfund Research Program (grant 5 P42 ES005948). We thank Stephen Richardson for assistance with the PAH analyses and Chad Roper for design of the method to measure desorption to the $\mathrm{C} 18$ disk. 


\section{References}

Aitken, MD.; Long, TC. Biotransformation, biodegradation and bioremediation of polycyclic aromatic hydrocarbons. In: Singh, A.; Ward, OP., editors. Soil Biology. Vol. Volume 2: iodegradation and Bioremediation. Springer-Verlag; Heidelberg, Germany: 2004. p. 83-124.

Alexander M. How toxic are toxic chemicals in soil. Environmental Science \& Technology. 1995; 29:2713-2717. [PubMed: 22206515]

Alexander M. Aging, bioavailability, and overestimation of risk from environmental pollutants. Environmental Science \& Technology. 2000; 34:4259-4265.

Boffetta P, Jourenkova N, Gustavsson P. Cancer risk from occupational and environmental exposure to polycyclic aromatic hydrocarbons. Cancer Causes \& Control. 1997; 8:444-472. [PubMed: 9498904]

Bostrom CE, Gerde P, Hanberg A, Jernstrom B, Johansson C, Kyrklund T, Rannug A, Tornqvist M, Victorin K, Westerholm R. Cancer risk assessment, indicators, and guidelines for polycyclic aromatic hydrocarbons in the ambient air. Environmental Health Perspectives. 2002; 110:451-488. [PubMed: 12060843]

Bunge, AL.; Parks, JM. Soil contamination: Theoretical description. In: Roberts, MS.; Walters, KA., editors. Dermal Absorption and Toxicity Assessment. Marcel Decker, Inc.; New York: 1998. p. 669-696.

Cornelissen G, Gustafsson O, Bucheli TD, Jonker MTO, Koelmans AA, Van Noort PCM. Extensive sorption of organic compounds to black carbon, coal, and kerogen in sediments and soils: Mechanisms and consequences for distribution, bioaccumulation, and biodegradation. Environmental Science \& Technology. 2005; 39:6881-6895. [PubMed: 16201609]

Cornelissen G, Rigterink H, Ferdinandy MMA, Van Noort PCM. Rapidly desorbing fractions of PAHs in contaminated sediments as a predictor of the extent of bioremediation. Environmental Science \& Technology. 1998; 32:966-970.

Duff RM, Kissel JC. Effect of soil loading on dermal absorption efficiency from contaminated soils. Journal of Toxicology and Environmental Health. 1996; 48:93-106. [PubMed: 8637061]

Hawthorne SB, Poppendieck DG, Grabanski CB, Loehr RC. PAH release during water desorption, supercritical carbon dioxide extraction, and field bioremediation. Environmental Science \& Technology. 2001; 35:4577-4583. [PubMed: 11757619]

He X, Chen S, Quan X, Zhao YZ, Zhao HM. Temperature-dependence of soil/air partition coefficients for selected polycyclic aromatic hydrocarbons and organochlorine pesticides over a temperature range of-30 to+30 degrees C. Chemosphere. 2009; 76:465-471. [PubMed: 19395063]

Hippelein M, McLachlan MS. Soil/air partitioning of semivolatile organic compounds. 2. Influence of temperature and relative humidity. Environmental Science \& Technology. 2000; 34:3521-3526.

Loehr RC, Lamar MR, Poppendieck DG. A protocol to estimate the release of anthropogenic hydrocarbons from contaminated soils. Environmental Toxicology and Chemistry. 2003; 22:22022208. [PubMed: 12959552]

McKone TE, Howd RA. Estimating dermal uptake of nonionic organic chemicals from water and soil. 1. Unified fugacity-based models for risk assessments. Risk Analysis. 1992; 12:543-557. [PubMed: 1480800]

Meijer SN, Shoeib M, Jantunen LMM, Jones KC, Harner T. Air-soil exchange of organochlorine pesticides in agricultural soils. 1. Field measurements using a novel in situ sampling device. Environmental Science \& Technology. 2003; 37:1292-1299.

Ribes S, Van Drooge B, Dachs J, Gustafsson O, Grimalt JO. Influence of soot carbon on the soil-air partitioning of polycyclic aromatic hydrocarbons. Environmental Science \& Technology. 2003; 37:2675-2680. [PubMed: 12854704]

Richardson SD, Aitken MD. Desorption and bioavailability of PAHs in contaminated soil subjected to long-term in situ biostimulation. Environmental Toxicology and Chemistry. 2011; 30:2674-2681. [PubMed: 21932296]

Roy TA, Krueger AJ, Taylor BB, Mauro DM, Goldstein LS. Studies estimating the dermal bioavailability of polynuclear aromatic hydrocarbons from manufactured gas plant tarcontaminated soils. Environmental Science \& Technology. 1998; 32:3113-3117. 
Roy TA, Singh R. Effect of soil loading and soil sequestration on dermal bioavailability of polynuclear aromatic hydrocarbons. Bulletin of Environmental Contamination and Toxicology. 2001; 67:324331. [PubMed: 11479660]

Santodonato J. Review of the estrogenic and antiestrogenic activity of polycyclic aromatic hydrocarbons: Relationship to carcinogenicity. Chemosphere. 1997; 34:835-848. [PubMed: 9569946]

Schwarzenbach, RP.; Gschwend, PM.; Imboden, DM. Environmental Organic Chemistry. WileyInterscience; Hoboken, NJ, U.S.A.: 2003.

Shatkin JA, Wagle M, Kent S, Menzie CA. Development of a biokinetic model to evaluate dermal absorption of polycyclic aromatic hydrocarbons from soil. Human and Ecological Risk Assessment. 2002; 8:713-734.

Sobus JR, McClean MD, Herrick RF, Waidyanatha S, Nylander-French LA, Kupper LL, Rappaport SM. Comparing urinary biomarkers of airborne and dermal exposure to polycyclic aromatic compounds in asphalt-exposed workers. Annals of Occupational Hygiene. 2009; 53:561-571. [PubMed: 19602502]

Spalt EW, Kissel JC, Shirai JH, Bunge AL. Dermal absorption of environmental contaminants from soil and sediment: a critical review. Journal of Exposure Science and Environmental Epidemiology. 2009; 19:119-148. [PubMed: 18830234]

Stroo HF, Jensen R, Loehr RC, Nakles DV, Fairbrother A, Liban CB. Environmentally acceptable endpoints for PAHs at a manufactured gas plant site. Environmental Science \& Technology. 2000; 34:3831-3836.

Touraille GD, McCarley KD, Bunge AL, Marty JP, Guy RH. Percutaneous absorption of 4cyanophenol from freshly contaminated soil in vitro: Effects of soil loading and contamination concentration. Environmental Science \& Technology. 2005; 39:3723-3731. [PubMed: 15954226]

USEPA. Risk Assessment Guidance for Superfund Volume I: Human Health Evaluation Manual (Part E, Supplemental Guidance for Dermal Risk Assessment). Washington, DC: 2004.

Wester RC, Maibach HI, Bucks DAW, Sedik L, Melendres J, Liao C, Dizio S. Percutaneousabsorption of [C-14] DDT and [C-14] benzo[a]pyrene from soil. Fundamental and Applied Toxicology. 1990; 15:510-516. [PubMed: 2258015]

Xing BS, Pignatello JJ. Dual-mode sorption of low-polarity compounds in glassy poly(vinyl chloride) and soil organic matter. Environmental Science \& Technology. 1997; 31:792-799.

Yang WL, Holmen BA. Relative effects of surfactants and humidity on soil/air desorption of chloroacetanilide and dinitroaniline herbicides. Environmental Science \& Technology. 2008; 42:6843-6848. [PubMed: 18853798]

Zhu HB, Roper JC, Pfaender FK, Aitken MD. Effects of anaerobic incubation on the desorption of polycyclic aromatic hydrocarbons from contaminated soils. Environmental Toxicology and Chemistry. 2008; 27:837-844. [PubMed: 18333673] 


\section{Highlights}

- We evaluated PAH desorption from field-contaminated soil to a hydrophobic surface.

- PAHs desorbed at soil loadings in excess of monolayer coverage.

- Transport of PAHs through the vapor phase is an important mechanism.

- Bioremediation eliminates PAHs capable of desorbing to the hydrophobic surface. 


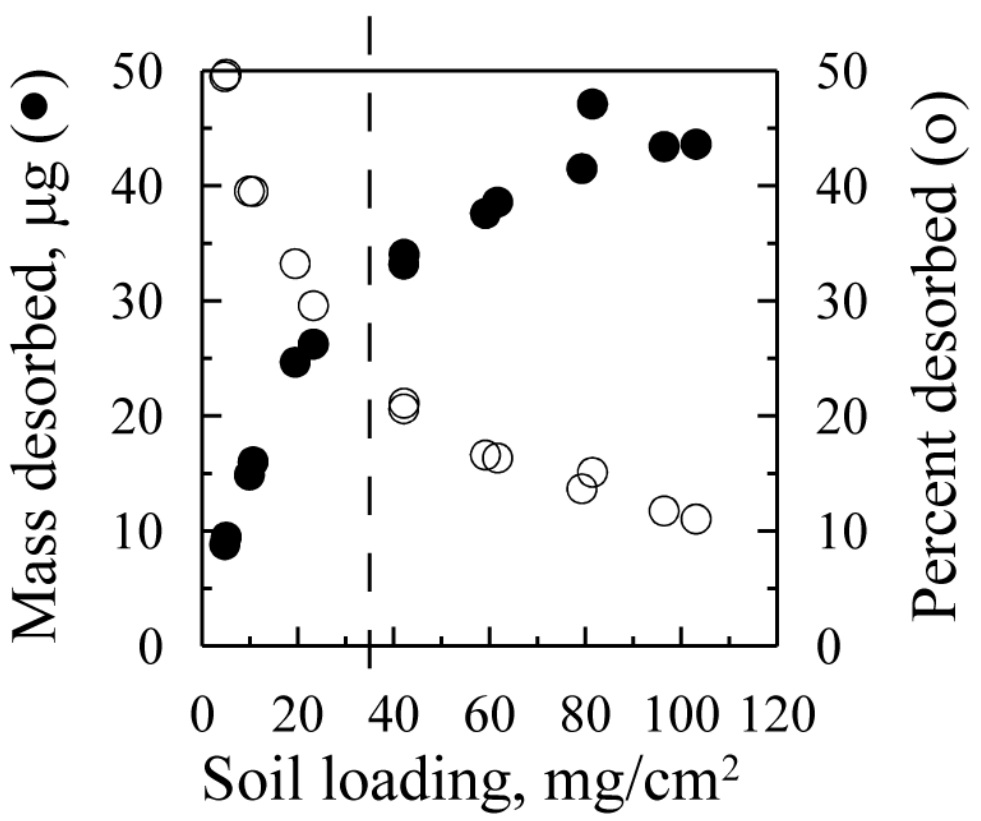

Fig. 1.

Total PAHs desorbed from source soil to $\mathrm{C} 18$ extraction disks as a function of soil loading. Soil moisture content was $2 \%$, temperature $20{ }^{\circ} \mathrm{C}$ and contact time $6 \mathrm{~d}$. Dashed vertical lines indicate the estimated maximum monolayer coverage of $34 \mathrm{mg} / \mathrm{cm}^{2}$. 


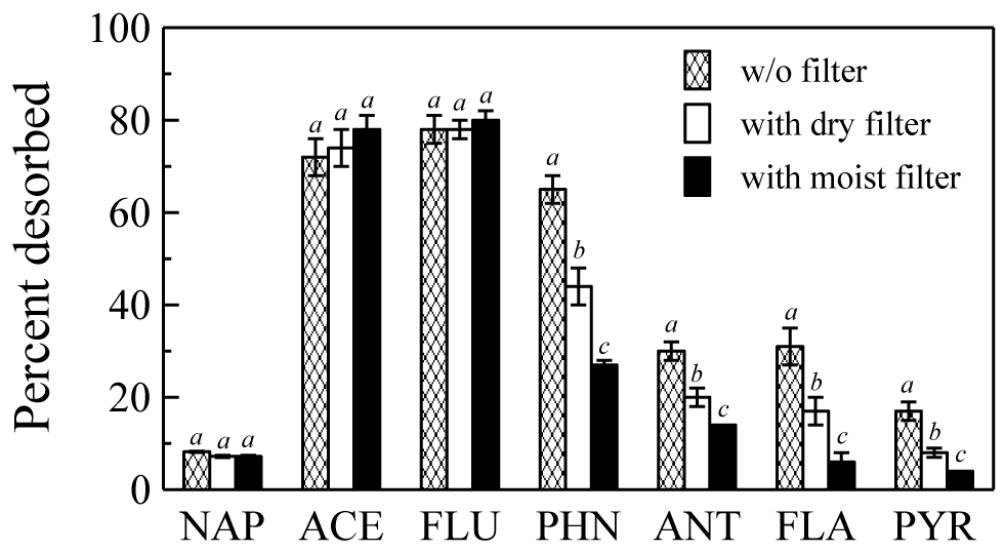

Fig. 2.

Desorption of PAHs to $\mathrm{C} 18$ disks from source soil with or without a glass microfiber filter placed between the $\mathrm{C} 18$ disk and the soil. Soil moisture content was $2 \%$, soil loading $40 \mathrm{mg}$ / $\mathrm{cm}^{2}$, temperature $20^{\circ} \mathrm{C}$, and contact time $6 \mathrm{~d}$. Desorption was less than $2 \%$ for $\mathrm{BaA}, \mathrm{CHR}$, $\mathrm{B} b \mathrm{~F}, \mathrm{~B} k \mathrm{~F}, \mathrm{~B} a \mathrm{P}, \mathrm{DBA}$ and $\mathrm{B} g \mathrm{P}$ under all three conditions. The same letter is assigned to conditions for which there was no significant difference $(p>0.05)$. 


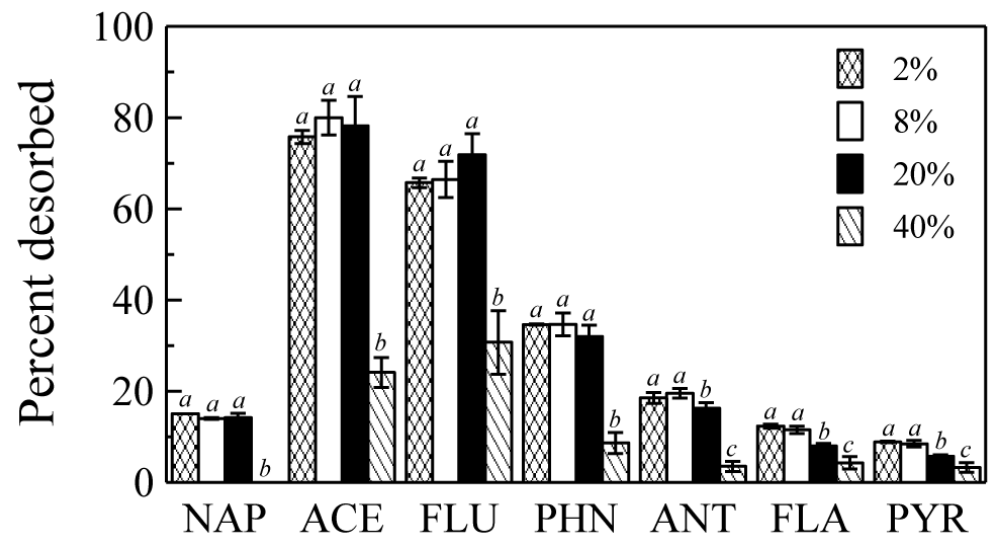

Fig. 3.

Effect of soil moisture content on desorption of PAHs to C18 disks from source soil. Soil loading was $50 \mathrm{mg} / \mathrm{cm}^{2}$, temperature $20{ }^{\circ} \mathrm{C}$, and contact time $6 \mathrm{~d}$. Desorption was less than $2 \%$ for $\mathrm{B} a \mathrm{~A}, \mathrm{CHR}, \mathrm{B} b \mathrm{~F}, \mathrm{~B} k \mathrm{~F}, \mathrm{~B} a \mathrm{P}, \mathrm{DBA}$ and $\mathrm{B} g \mathrm{P}$ under all four conditions. The same letter is assigned to conditions for which there was no significant difference $(p>0.05)$. 


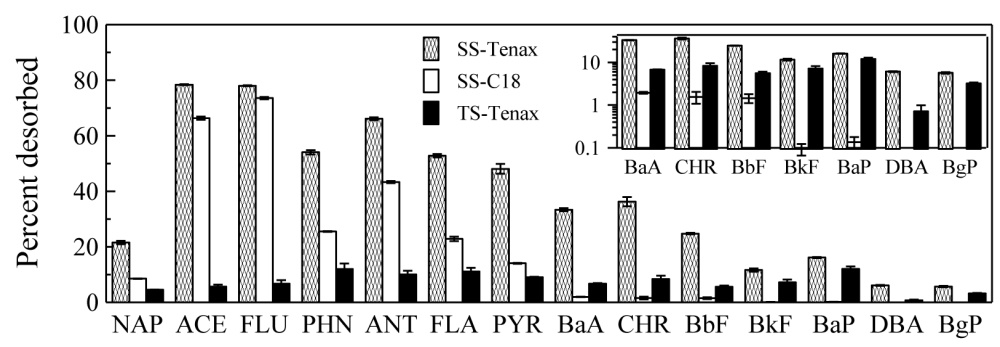

Fig. 4.

Desorption of individual PAHs from source soil to Tenax beads (SS-Tenax) or to C18 disks (SS-C18) or from biologically treated soil to Tenax beads (TS-Tenax). The inset enlarges the results for higher molecular weight PAHs. All measurements were at $20{ }^{\circ} \mathrm{C}$ at a $16-\mathrm{d}$ contact time. For desorption to $\mathrm{C} 18$ disks, soil moisture content was $2 \%$ and soil loading 50 $\mathrm{mg} / \mathrm{cm}^{2}$. Desorption to $\mathrm{C} 18$ disks from biologically treated soil was not detectable. 